JWAM

11,2

106

Received 2 August 2019 Accepted 9 August 2019

\section{The nature of work-related problems: messy, co-produced and wicked}

\author{
Lee Fergusson \\ University of Southern Queensland, Springfield, Australia
}

\begin{abstract}
Purpose - Work-based research is the applied form of work-based learning (WBL) and has been described as the systematic and methodical process of investigating work-related "problems". Such problems can either be associated with specific workplaces and domains of practice or may more broadly be described as practical, social or real-world in nature. However, the specific characteristics of work-related problems for organisations and society have yet to be explained, and inadequate problem definition, multiple and competing goals, and lack of agreement on cause-effect relationships have hampered understanding. The purpose of this paper is to examine the nature of work-related problems and provides examples from real-world contexts in Australia. Design/methodology/approach - The paper provides models and examples of standard and non-standard work-related problems based on prior research and current practice.

Findings - Research paradigms view work-related problems as either definable and solvable or ill-defined, complex, difficult to describe and not easily rectified. The former view is concerned with "high ground problems" associated with traditional research methods; the latter with "lowland, messy, confusing problems" more frequently associated with the social sciences. Irrespective of orientation and definition, work-related problems have one thing in common: they are typically messy, constantly changing and complex, and many are co-produced and wicked.

Originality/value - Despite difficulties with identifying and isolating the various types of work-related problem, the paper establishes the importance of doing so for the practitioner. The definition and examination of work-related problems contribute to an evolving formulation of WBL and its application to private organisations, government agencies and work more generally.
\end{abstract}

Keywords Work-based learning, Work-related problem, Wicked problem, Co-produced problem, Messy problem, Work-based research

Paper type Research paper

\title{
Introduction
}

The published literature on work-based learning (WBL) and its impact on contemporary workplaces and domains of practice, is extensive. Over a 20-year period, analyses of the WBL philosophy and pedagogy have included reflections on insider research (Costley et al., 2010), the nature of prior learning and experience (Armsby et al., 2006), and competency and capability (Lester and Chapman, 2008), and have explored its relation to workplace learning and work-related learning (Allan, 2015). WBL has even been assessed in terms of Confucian principles (Sun and Kang, 2015), and has sometimes been cast in the mould of so-called "Mode 2 learning", in which "knowledge is, by its very nature, focused on real world issues and problems and, as such, takes a multi-disciplinary approach, which emphasises the applied nature of knowledge production" (Fulton and Hayes, 2017, p. 4).

As a consequence of its organisational and human concerns, emphases in WBL have been placed on reflective practice (Siebert and Walsh, 2013), learning contracts (Gibbs, 2009) and models of the self-managed or researching practitioner (Lester and Costley, 2010).

\footnotetext{
(C) Lee Fergusson. Published in Journal of Work-Applied Management. Published by Emerald Publishing Limited. This article is published under the Creative Commons Attribution (CC BY 4.0) licence. Anyone may reproduce, distribute, translate and create derivative works of this article (for both commercial and non-commercial purposes), subject to full attribution to the original publication and authors. The full terms of this licence may be seen at http://creativecommons.org/licences/by/4.0/legalcode 
Its relation to broader social and political change, including the re-engagement of disadvantaged youth through WBL (Thompson, 2011) and to higher education more generally where it has been linked with so-called "practitioner doctorates" (Lester, 2012), has also been explored. Raelin (2011, p. 17) therefore proposes that WBL is not simply a pedagogical approach to learning but "a philosophical approach that characterises how learners develop their knowledge to participate effectively and democratically in a civil society. It is concerned with how to make learning arise from our mutual experience with others, in particular, from our work together". To that end, he argues "in work-based learning, theory is expressly merged with practice, while knowledge is considered to be fluid and changeable. Learning is centered on reflection on work practices. Hence, it offers practitioners faced with the relentless pace of pervasive change an opportunity to overcome time pressures by reflecting upon and learning from the artistry of their action" (p. 17).

However, more recently WBL has been focused on work-related "problems" (e.g. Toledano-O'Farrill, 2017), what Costley et al. (2010, p. 8) called "practical problems" related to workplaces, domains of practice, and the world of work more generally. Raelin (2008, p. 3) similarly suggests that the metacognitive features of WBL mean "one constantly thinks about one's problem-solving process". This focus in WBL has adopted the view that work-related problems can either be "solved" using formal, analytical practices (what I call the standard academic view of problem solving) or the messiness of work-related problems creates unique challenges, and such problems are complex, ill-defined, difficult to describe and thus not easily rectified (the non-standard academic view of problem solving). Donald Schön (1995, p. 233) proposed that the standard view considers "high ground problems" which tend to be relatively unimportant to individuals or society however great their technical merit, while the non-standard view is one of "lowland, messy, confusing problems" which defy technical solutions but are of greater human concern. His challenge to the practitioner was: do we "remain on the high hard ground working in a rigorous, describable way on relatively trivial problems or [should we] leap into the swamp and work on the problems we see as critically important”?

In the standard academic view, a work-related problem can be addressed, ameliorated or rectified, and recommendations for the future can be made with confidence. For example, Blackman (2016, pp. 2-3) calls this view when applied to WBL "practical, creative problem solving that explores alternative solutions for a better future [...]". In order to understand and rectify a problem, according to this view, "the factors that influence [the problem] have to be identified, described and explored in depth to see where the problem originated and what range of alternatives might be offered" (Costley et al., 2010, p. 18). This formal analytical process, the authors argue, requires the researcher to "explore the internal, external, social and institutional processes that combine to form a particular event, and to take a logical approach to see how these processes could be expected to contribute to the behaviour of those involved. This can be used to create a strategy to resolve the problem" (p. 18). The standard view adopts such conventions as logic, optimality models, redesigned systems, strategies and frameworks to help work-based researchers scaffold their arguments and offer workable solutions, and early WBL evidence of it can be found in the work of Nixon et al. (2006).

In what I am terming the non-standard academic view, work-related problems are regarded entirely differently because they are said to exist in constantly changing, unstable environments and, as Russell Ackoff (1979) pointed out 40 years ago, any potential solution to such problems is necessarily short-lived. In this case:

The structure and the parameters of problematic situations continuously change, particularly in turbulent environments. Because optimal solutions are very seldom made adaptive to such changes, their optimality is generally of short duration. They frequently become less effective than were the often more robust solutions that they replace. Let us call this cross-over point the moment of death of the solution. (p. 79) 
JWAM

11,2

108

Ackoff went on to explain that as a result of this "cross-over point":

$[\ldots]$ the life of solutions to many critical social and organizational problems is shorter than the time required to find them. Therefore, more and more so-called optimal solutions are still-born. With the accelerating rate of technological and social change dramatized by Alvin Toffler and others, the expected life of optimal solutions and the problems to which they apply can be expected to become increasingly negative. (p. 79)

As a consequence, not only can solutions to non-standard work-related problems be short-lived beyond the "moment of death" but "some of the solutions advocated by professional experts [...][create] problems as bad as or worse than those they had been designed to solve" (Schön, 2016, p. 10). Thus, according to the non-standard view, causes, effects and solutions are never straightforward nor are they easily modelled.

The environments in which this type of non-standard, but increasingly common, problem exist (i.e. contemporary workplaces or domains of practice) are what Ackoff and others call "messy" situations, in which solutions are characterised by "multiple and competing goals, little scientific agreement on cause-effect relationships, limited time and resources, lack of information, and structural inequities in access to information and the distribution of political power" (Lachapelle et al., 2003, p. 473). To this classification we can add a lack of reliable data, difficulty arriving at agreed objectives, and many other uncertainties or limitations associated with messiness. In such environments, "[professionals] are confronted with a variety of troublesome and perplexing barriers in messy situations. Inadequate goal definition, lack of trust, procedural obligations, inflexibility, and broader issues relating to institutional design emerge as dominant themes [...]" (Lachapelle et al., 2003, pp. 487-488).

Moreover, messy work environments involve "values as much as data, and therefore not only are different skills required [to solve problems][...] but the very practice is constructed upon fundamentally different premises" (Lachapelle et al., 2003, p. 485). This is why Schön (2016, p. 4) pointed out that "professionally designed solutions to public problems [including problems associated with work] have had unanticipated consequences, sometimes worse than the problems they were designed to solve. Newly invented technologies, professionally conceived and evaluated, have turned out to produce unintended side effects unacceptable to large segments of our society". To this end, non-standard work-related problems require "non-traditional solutions" (Allen and Gould, 1986, p. 23). Hence, nearly five decades ago in the context of policy development, Rittel and Webber (1973, p. 155) pointed out that the standard academic view of problem solving has significant limitations and thus "the search for scientific bases for confronting problems of social policy is bound to fail, because of the nature of these problems":

They are "wicked" problems, whereas science has developed to deal with "tame" problems. Policy problems cannot be definitively described. Moreover, in a pluralistic society there is nothing like the undisputable public good; there is no objective definition of equity; policies that respond to social problems cannot be meaningfully correct or false; and it makes no sense to talk about "optimal solutions" to social problems unless severe qualifications are imposed first. Even worse, there are no "solutions" in the sense of definitive and objective answers. (p. 155)

The distinction between what I am calling the standard and non-standard academic views of work-related problems can also be found in the worldviews of researchers who seek to define and examine them. As shown in simplified form by Figure 1(a), of the possible paradigms guiding research in work-based projects three dominate: Social Constructivism, Participatory and Pragmatism. Certainly, Postpositivist research is possible within the WBL framework, such as that associated with the recent Australian example conducted by a personal trainer investigating lower-limb sports injuries in children and how to prevent them, however these are less common. 
(a)

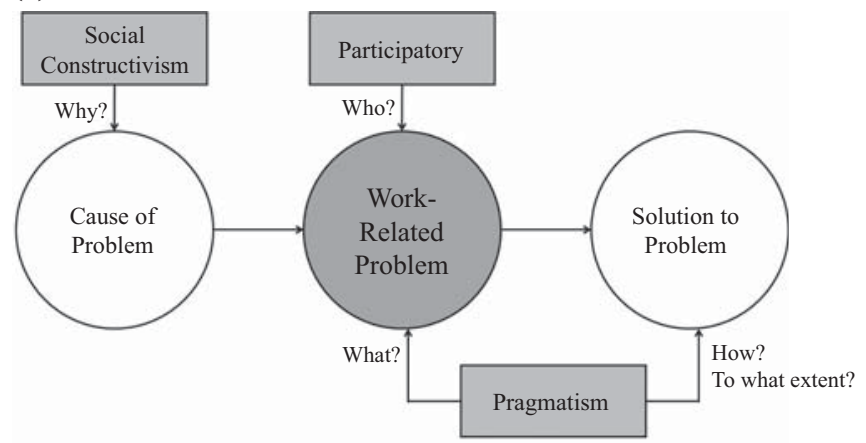

(b)

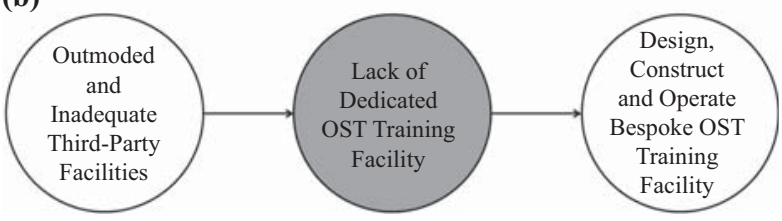

The nature of work-related problems

According to Werhane et al. (2011, p. 103), "one of the dominant contemporary theories in [...] the social sciences is called 'social constructivism'":

The thesis of social constructivism is that our minds do not mirror experience or reality. Rather, our minds project and reconstitute experience. The idea of mental models, the basis for social constructivism, emerged from the social constructivist conclusion that the human mind organizes and orders its experiences, and that human knowledge is based on these constructions, as opposed to what may or may not exist apart from our experiences in the external world. (p. 103)

In Social Constructivism then, multiple meanings and realities, and any understanding of a work-related problem or its cause, are organised and ordered by the researcher and may exist apart from the real-world problem. Such an orientation to research, in which meanings and problem definition are constructed with focus mostly on "why" research questions, does not suggest itself to the standard academic view of work-related problems and their solutions.

Similarly, through a Participatory lens, problems are political and issues oriented; as Hawkins (2015, p. 464) points out, "Participatory action research (PAR) is not an easy undertaking for any participant. Indeed, it is often referred to as messy and complex". In work environments, change is viewed as collaborative and non-linear, and hence problem solving while possible is not as logical, objective or straightforward as posited by the standard academic view. Around 25 years ago, Cornwall and Jewkes (1995, p. 1667) gave the example of "participatory mapping" to reveal:

$[\ldots]$ the single most striking difference between participatory and conventional methodologies. This lies less in the theories which inform these methodological frameworks or even in the methods they use but in who defines research problems and who generates, analyses, represents, owns and acts on the information which is sought. Asking the "who?" question enables us to look more closely at what is meant by participatory research. It focuses attention on the central issues of power and control.

A good example of such research is provided by Lelieveldt et al. (2009) in eight Dutch communities which showed that neighbourhood and organisational problem solving was more associated with the co-production of solutions by participants than it was through the 
JWAM

11,2

110

allocation of resources (a solution more typically advocated within the standard view, particularly by policy makers). On the other hand, work-based research seen through a Pragmatist lens (the single most common WBL paradigm), seeks to identify solutions to problems, and to make recommendations and improvements related to them; in this orientation the consequences of action are highlighted. Thus, Pragmatism mostly asks "what", "how" and "to what extent" research questions and is therefore well aligned to the standard academic view of decision making and problem solving. However, Ioannidis (2016, p. 1) points out that many of the features that should make applied research useful, including "those relating to problem base, context placement, information gain, pragmatism [...] value for money, feasibility, and transparency" often fail to materialise. Ioannidis (2016, p. 2) thus questions whether research projects viewed through a Pragmatist lens truly "reflect real life". Thus, in WBL cases regardless of paradigmatic approach, "what can be most helpful to practitioners is not a pure scientific method which attempts to objectify all organizational phenomena but an applied science which takes into consideration the cultural, political, and moral dilemmas within our social systems" (Raelin, 1997, p. 568).

In summary, WBL and the work-based research which accompanies it point to a concern for problems but rarely, if at all, does it articulate what those problems actually are other than in the broadest possible terms. When it does approach a problem, it usually encourages behaviours such as "on-the-spot reframing [of the problem], re-evaluation of past experiences, or spontaneous testing of available knowledge to arrive at a solution to the immediate problem" (Raelin, 2008, p. 19). The purpose of this paper therefore is to detail the nature of work-related problems in the context of not only Achoff's "messy" model but also in relation to the potential for problems to be co-produced and wicked. I do so by furnishing examples from a WBL postgraduate programme in Australia in order to substantiate the concepts in relation to problems in contemporary work environments. The site for this investigation will be the Professional Studies higher degree by research (HDR) programme at University of Southern Queensland in Australia, which has been well documented elsewhere (Fergusson et al., 2018; Fergusson, van der Laan and Baker, 2019; Fergusson, van der Laan, White and Balfour, 2019).

\section{Standard academic view of work-related problems}

Solving problems is an innate human instinct and viewing problems as solvable is perhaps as equally innate. As shown in Figure 1 the relationship of cause, effect and solution in the standard academic view is well-understood and straightforward. Often beginning with a "problem statement" and setting a goal through experience coupled with an understanding of the cause of the problem, one's knowledge and skill can be brought to bear on finding a solution to it. Such a view was suggested 20 years ago by Raelin $(1997$, p. 563) when he observed of WBL that "learning acquired through experience, often referred to as implicit learning, is the foundation for tacit knowledge and can be used to solve problems as well as make reasonable decisions about novel situations [but] reflection is required to bring the inherent tacit knowledge of experience to the surface". In Raelin's example, "implicit learning" is the "acquisition of complex knowledge that takes place without the learner's awareness that he or she is learning", and "tacit knowledge" is the "component of overall knowledge normally not reportable since it is deeply rooted in action and involvement in a specific context" (p. 563). Thus, the standard academic view of work-related problems accepts that causes and solutions can and are discoverable, connected and linear, although less conventional views and approaches within the standard view, such as those utilising collaborator problem solving (Häkkinen et al., 2017), have also been investigated.

In the Professional Studies programme, such views are not uncommon. For example, in a current HDR research project the practitioner (RW, a Superintendent of counter terrorism in the Queensland Police Service (QPS)) is investigating the implementation of a new operational skills and tactics (OST) training centre through a Pragmatist lens. As shown in 
Figure 1(b), the problem and its cause are clearly defined and well understood: a lack of appropriate OST training facilities in Queensland caused by outmoded, disparate and inadequate third-party provider facilities. The solution is equally straightforward: design, construct and operate a bespoke OST training facility for the QPS based on an investigation of international best practice. In such projects, the goal is clear, time and resources are defined, and information is transparent. The HDR project in question therefore considers the entire logical value-chain of events leading to the solution by asking what the new facility will look like and how and to what extent it will meet current and future OST training needs. Unlike projects associated with the non-standard view which require either multidisciplinary or even transdisciplinary approaches, standard work-related problems are "discipline" specific, in this case using the well-established practice of designing and constructing what are called Counter Terrorism and Community Safety Centres.

In summary, the standard view of a work-related problem suggests: it can be defined; its causes are (or can be) known; and viable and practical solutions can be sought, developed and applied. The aim of such an approach is organisational and social improvement, however these three related features of "tame" work-related problems are not automatically or universally accepted in non-standard environments.

\section{Non-standard academic view of work-related problems}

As discussed above, the non-standard view of work-related problems is of an entirely different ilk: problems are, according to this mindset, always messy but can also be co-produced and wicked (or even super-wicked). These types of problems, which are common to contemporary workplaces and domains of practice, in addition to being difficult to define require multidisciplinary or transdisciplinary methods due to the multifarious goals and organisational complexity associated with them. For this reason, "integrating a range of knowledges, methodologies, and learning can reveal intersections and blind spots that single disciplinary research is unable to do" (Vogel et al., 2016, p. 516). Hence WBL's interest in learning and research which require "a combination of rational analysis and imagination and intuition" (Raelin, 2008, p. 3). In the following section we discuss the nature of non-standard work-related problems as they have been considered by WBL.

\section{Messy work-related problems}

In keeping with Ackoff's analysis of messy situations, Figure 2(a) attempts to graphically represent a messy problem embedded in a world of work, in what Rosenhead (1992, p. 293) after Schön called a "swamp". In this diagram, work is embedded within the broader parameters and machinations of society, and work-related problems and their causes are represented without distinct boundaries to illustrate their ill-defined nature. According to Haskins (2006), such problems and causes are constantly changing, often politicised, fuzzy or even disputed, and therefore difficult to describe; attempts to define and describe them are "muddled by basic human nature" (p. 11) and therefore it is "[un]reasonable to assume that all members of an organization accept the stated views and goals of its leaders" (p. 11). According to Haskins, these are the "ill-defined problem situations with which managers have to cope in their day-to-day professional lives" (p. 11).

According to Ginsburg (2012, p. 537), the orderly, standard approach to "design" implies a "technocratic architectural paradigm that does not easily fit the messy realities of social institutions" and hence agreement on how to tackle and solve problems associated with work environments is not always forthcoming. Any "elicitation approach" reflects "biases introduced by the methods used and starting positions [of stakeholders]. Eventual conclusions are [thus] clearly affected by human perception and commitments" (Haskins, 2006, p. 11).

Many work-related problems investigated in the Professional Studies programme are messy. While appearing to be a standard, quasi-experimental study using a non-randomised, controlled,
The nature of work-related problems 


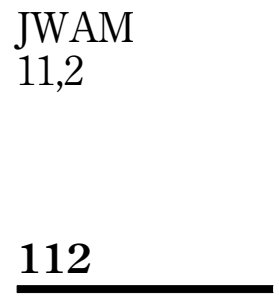

Figure 2.

Conceptual model (a) and example (b)

of a messy

work-related problem

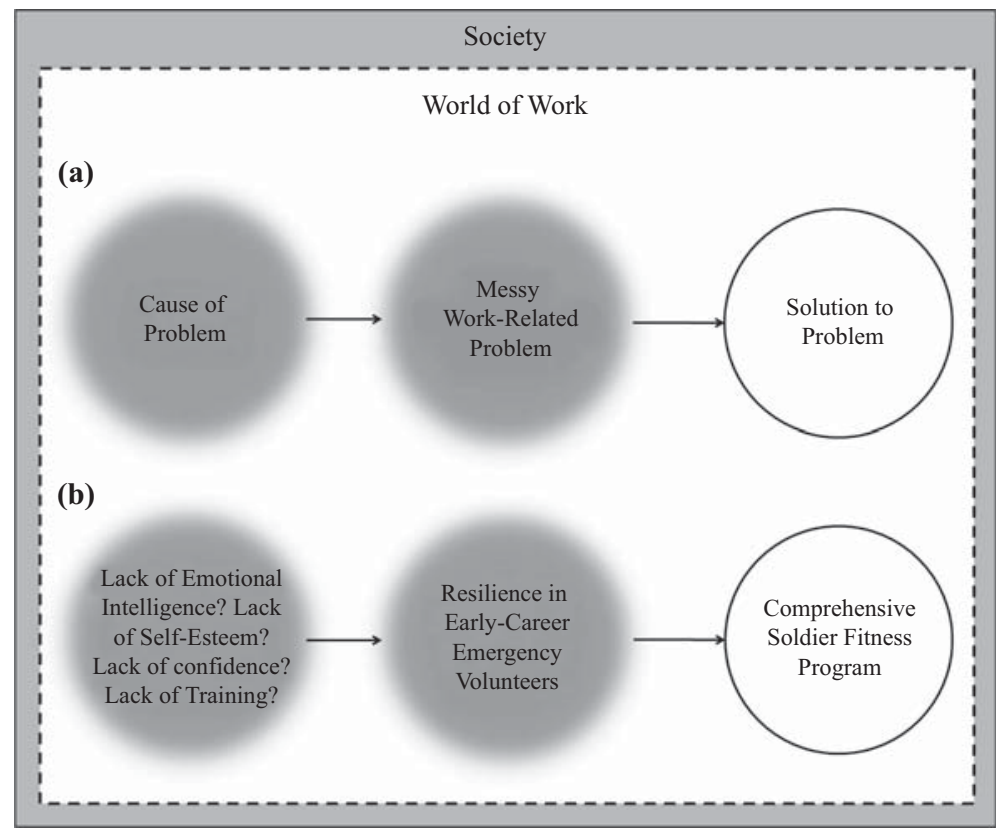

longitudinal design, the following WBL research project will illustrate this point. As shown in Figure 2(b), GM (an anaesthetist with 40 years' volunteer experience, much of it in Africa) is investigating resilience (or the lack of it) in early-career emergency first-responder volunteers, specifically fire-fighters and paramedics. What makes his project messy is a difficulty in describing or quantifying the problem, the ill-defined and multiple possible causes of resilience levels in volunteers (are they caused by lack of emotional intelligence or lack of self-esteem?), the reasons motivating individuals to volunteer for emergency services, the meaning of the construct "resilience" (is it based in physiology or psychology, or is it socially constructed, contextual and/ or culturally ambiguous?), the way resilience interacts with other workplace behaviours, and the unique characteristics of the emergency work space, among many other factors associated with this type of work. Moreover, there is little agreement about how to tackle and solve the problem of resilience in volunteers. While the study tests one alternative approach developed by the U.S. military, the so-called Comprehensive Soldier Fitness Programme, the nature of the environment means that not only is a mixed methods design required to gauge complexity but agreement on outcomes may be unlikely, reinforcing Haskins' earlier point about the members of an organisation accepting the views of its leaders.

\section{Co-produced work-related problems}

The term "co-produced" is used in relation to teams working together to identify and solve problems (Kempster and Stewart, 2010), transdisciplinarity (Polk, 2015) and is increasingly applied to the design of programs and services in the UK (Boyle and Harris, 2009). However, we use the term differently in this WBL context. According to Dostal et al. (2005, p. 7), "problems are always caused by a variety of factors. There is never a single cause to any problem situation". Most co-produced work-related problems are definitely messy, but they have the additional compounding feature of also being co-caused, as shown by the conceptual model presented in Figure 3(a). In this diagram, three causes produce the problem, with Causes 2 and 3 being equally responsible for the work-related problem and Cause 1 causing Cause 2. 


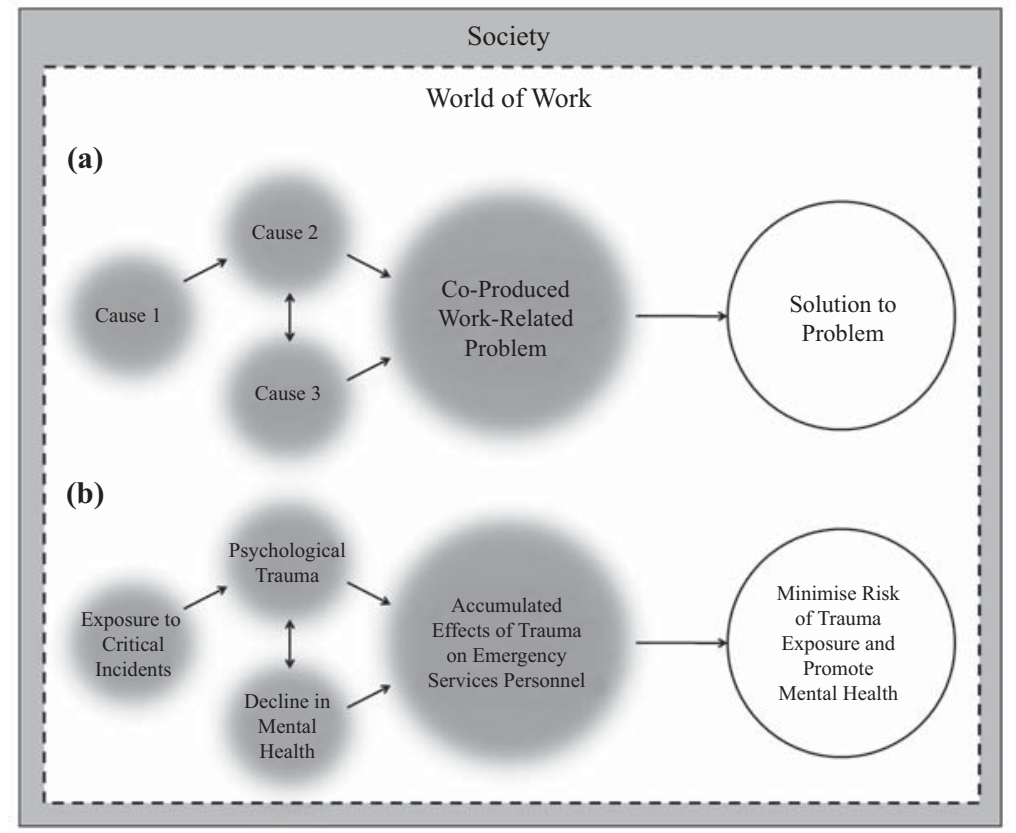

The nature of work-related problems

113

Figure 3.

Conceptual model (a) and example (b) of a co-produced work-related problem

Dostal et al. (2005, p. 7) use the analogy of an oak tree to explain this situation when they point out that an acorn is not the only cause of the tree; "co-producing factors (i.e. sufficient causes) include soil, nutrients, sunlight, water, protection from damage by animal, man, storms, lightening, etc." and each contributor, in the right amount at the right time, allows the tree to live and thrive. Dostal et al. (2005) point out the principle of co-production (also referred to as "multiple causation") can also differentiate necessary and sufficient causation. In their example, an acorn is a necessary, but not sufficient, cause of a tree. Stated differently: a tree cannot be a tree without a seed; it may require soil, water, nutrients and sunlight to thrive, but it can exist and grow without protection from animals. Note also that some of these co-produced factors can cause each other. For example, water liberates nutrients like phosphorus and nitrogen from soil thereby making them bioavailable to the roots of the tree, which help it grow. These distinctions are important in the work-related context because the messy nature of problems not only means causes are potentially co-produced but identifying and isolating them as necessary or sufficient is difficult (and sometimes all but impossible).

With work-related problems, as with other non-standard complex problems, causes and problems can (and often do) co-produce thereby creating "perplexing" situations because of "the mutual impact of problems on each other" (Dostal et al., 2005, p. 9). To make matters more troublesome, Dostal et al. (2012) point out that co-producing factors can also arise from outside the system in which the problem is embedded (e.g. from the environment outside a workplace, such as a change in government policy affecting the structure and function of a not-for-profit organisation) and in so doing impact or further compound and co-produce complexity in the problem. These types of circular cause-and-effect problems (or so-called "circular causation" problems) create "vicious circles" (Dostal et al., 2012, p. 119) and are akin to wicked problems for that reason.

Numerous examples of co-produced work-related problems exist within the Professional Studies programme. One project from a Constructivist perspective investigating the effects of trauma on emergency services personnel will serve as a more detailed example. According to RK 
JWAM

11,2

114

(a manager of critical incidents and peer support programs at Queensland Fire and Emergency Services (QFES)), emergency services organisations across Australia are striving to better understand and manage the complex challenges of mental health. As shown in Figure 3(b), exposure to trauma during critical incidents such as flood events and hurricanes can cause psychological trauma which adversely affects mental health, and both may have an accumulative effect on QFES personnel. The study seeks to find ways of minimising the risks of exposure and to promote better mental health. Research acknowledges that there are a host of contributing factors to mental health outcomes after exposure to trauma, hence the need for this study to better understand the psychosocial needs of QFES personnel in the context of disaster situations and extreme events. It is anticipated the research will provide an evidence base upon which to inform policy and make recommendations for quality practice that may be integrated into QFES's operational framework, thereby fostering enhanced mental health awareness and a more supportive organisational culture.

\section{Wicked work-related problems}

Wicked problems are often associated with complex social, political and environmental challenges, such as global heating, poverty, equity, social justice and food security, and not with work per se. However, some of the features discussed in contemporary literature about "wickedness" are encountered in workplaces and domains of practice, and Rittel and Webber's (1973) early application of the concept to social problems points to this conclusion, as does Farrell's (2011) more recent transdisciplinary approach.

Wicked problems share many of the same qualities of messy and co-produced problems, but also exhibit other characteristics. For example, Yearworth (2016) builds upon earlier definitions to point out that wicked problems: cannot be definitively formulated; display what he calls a "no stopping rule" (p. 38); suggest solutions that are neither right nor wrong, with no immediate or ultimate test of a solution (wicked problems can only be viewed as effective or ineffective); have "one-shot" solutions, and trials-and-error are impossible and thus every intervention is significant; do not generate enumerable, exhaustively describable, sets of solutions; are symptoms of other problems (i.e. problems, as well as causes, are co-produced); can be contested at the level of explanation and are likely to generate conflicting evidence; and always require intervention, and are therefore not associated with knowledge for its own sake.

Moreover, others point out that wicked problems are non-linear, highly complex and defy simple solution (although "provisional solutions" may be possible according to Head and Alford, 2015); any attempt at solving wickedness requires a multidisciplinary or transdisciplinary approach which "cannot be drawn from a single knowledge base" (Vogel et al., 2016, p. 515). Thus, wicked problems require a "science that builds knowledge through engagement with a variety of actors, their views, expertise and perspectives, including mutual and transgressive learning", what the authors call the "co-production of knowledge" (p. 515).

Like Yearworth, we use the term "wicked" in relation to work-related problems in the same way Rittel and Webber (1973) earlier defined it when they said:

We use the term "wicked" in a meaning akin to that of "malignant" (in contrast to "benign") or "vicious" (like a circle) or "tricky" (like a leprechaun) or "aggressive" (like a lion, in contrast to the docility of a lamb). We do not mean to personify these properties of social systems by implying malicious intent. But then, you may agree that it becomes morally objectionable [...] to treat a wicked problem as though it were a tame one, or to tame a wicked problem prematurely, or to refuse to recognize the inherent wickedness of social problems. (pp. 160-161)

Those involved with work, particularly its management, innovation and improvement, may identify with this definition. In its most extreme form, workplaces can be malignant and work-related problems vicious (e.g. Mehlman, 2006, in the case of chemical contamination in the workplace, and Schwarz and Kowalski, 1993, in the case of workplace shootings). 
To illustrate wickedness, we again locate work-related problems within the world of work and society in Figure 4. We show that a wicked work-related problem can (and usually is) made up of multiple messy problems (WRPs 1-4) and may be so complex that efforts to define and address them can result in multiple, sometimes overlapping, solutions. In this sense, not only may wicked problems be co-produced, they also can result in solutions which are complex and interdisciplinary in nature. Figure 4's model seeks to illustrate how multi-causation can play a major or minor role in creating the wicked work-related problem.

It must be said that research into wicked work-related problems is relatively recent and not widespread. Certainly, the work of Jespersen et al. (2016, p. 23) on the "significant" and wicked nature of psychosocial risks and mental health problems associated with "most workplaces", and O'Brien et al.'s (2017, p. 14717) research on the wicked problem of gender inequality which arises from "interactions between multiple context-specific factors [and] is both a symptom and a cause of other problems with disagreement and ambiguity around what constitutes success in reaching gender equality", are good examples of wickedness in contemporary work situations. However, it is also fair to say that most work-related problems are more likely to be messy and co-produced than wicked.

Nevertheless, investigations of wicked problems are not unknown in WBL, and at least one such problem has been examined in the Professional Studies programme. Figure 5 begins to conceptually unpack the nature of workplace drug addiction, which meets the accepted global standard of being a malignant, vicious and aggressive problem. Moreover, the nature of addiction and its relation to specific drugs has proven particularly "tricky" to comprehend, as discussed by Bjerg (2008, p. 3).

MP is a collaborative peer recovery coach who operates an addiction treatment charity in Queensland. Her important research considers the multiple causes of drug addiction, the
The nature of work-related problems

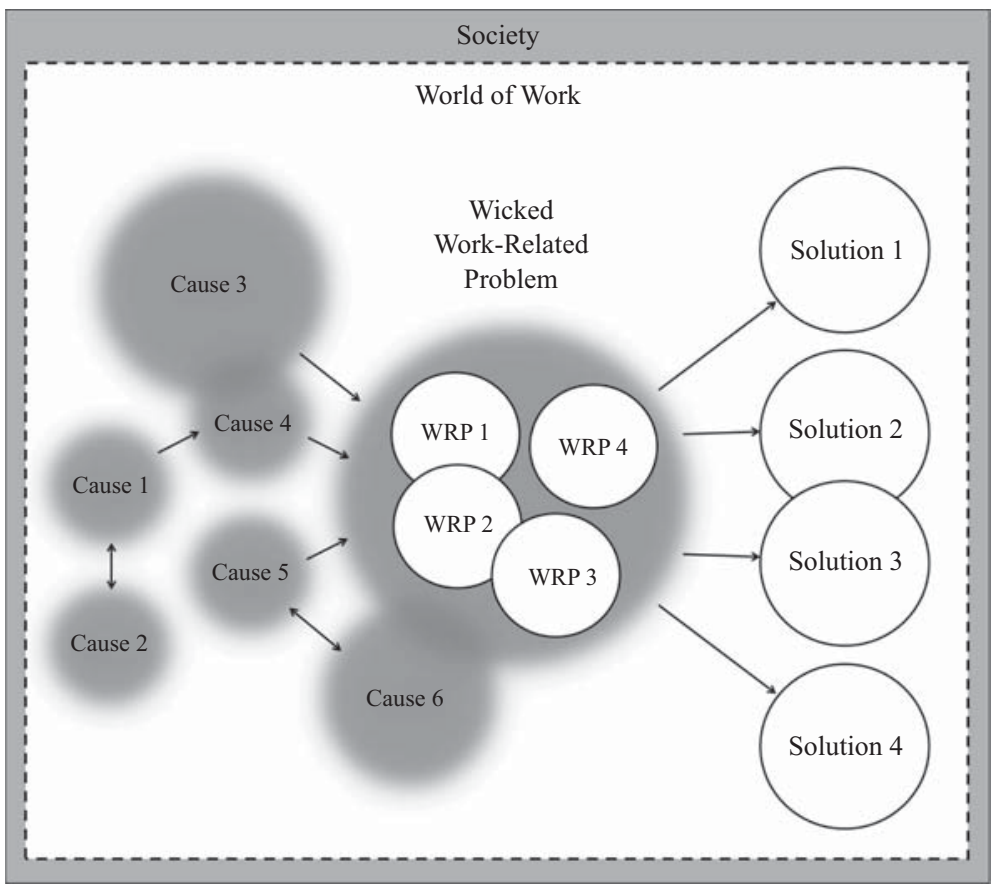

Figure 4 .

Proto-theoretical model of a wicked work-related problem 
JWAM

11,2

\section{6}

Figure 5.

Conceptual model of drug addiction as an example of a wicked work-related problem complex nature of the problem, and tentatively proposes a variety of possible pathways (rather than specific solutions) to addressing the problem using a Pragmatist paradigm.

Figure 5 shows that drug addiction is actually an interaction of several sub-WRPs, which may also co-produce each other, including availability of drugs, abuse disorders, long-term impairment to decision making, and a lack of effective screening and inadequate focus on treatment, each mixed with a lack of sobriety which underpins behaviour. Figure 5 also shows, among other things, that drug addiction is related to mental health by mutual causation and can be caused by trauma and impacted by denial mechanisms which in turn may have an epigenetic source. Addiction is typically co-morbid and is adversely impacted by ingrained habitual behaviours, both of which have been conceptually illustrated in Figure 5 to show their coproducing relationships, with co-morbidity also overlapping as a problem with/of addiction itself. Results from the research point to the need for further research and the exploration of other pathways to rehabilitation, including the need for a "therapeutic alliance" and focus on the ten dimensions of so-called "resource recovery capital".

A variation on this type of problem is the super-wicked problem which, according to Levin et al. (2012) is a wicked problem with four additional features: time is running out to find a solution to the problem; those who cause the problem are also the ones trying to solve it; the authority needed to address the problem is weak or non-existent; and responses to the problem are irrational, lack evidentiary support, and dangerously discount the significance of the problem's wickedness. "These four features combine to create a policy-making "tragedy" where traditional analytical techniques are ill equipped to identify solutions, even when it is well recognized that actions must take place soon to avoid catastrophic future impacts" (p. 123).

An obvious and well-publicised super-wicked problem is human-induced climate change (Lazarus, 2008), although sustainability more generally has also been referred to as super wicked (Yearworth, 2016). Given their relation to policy and civil action, super-wicked

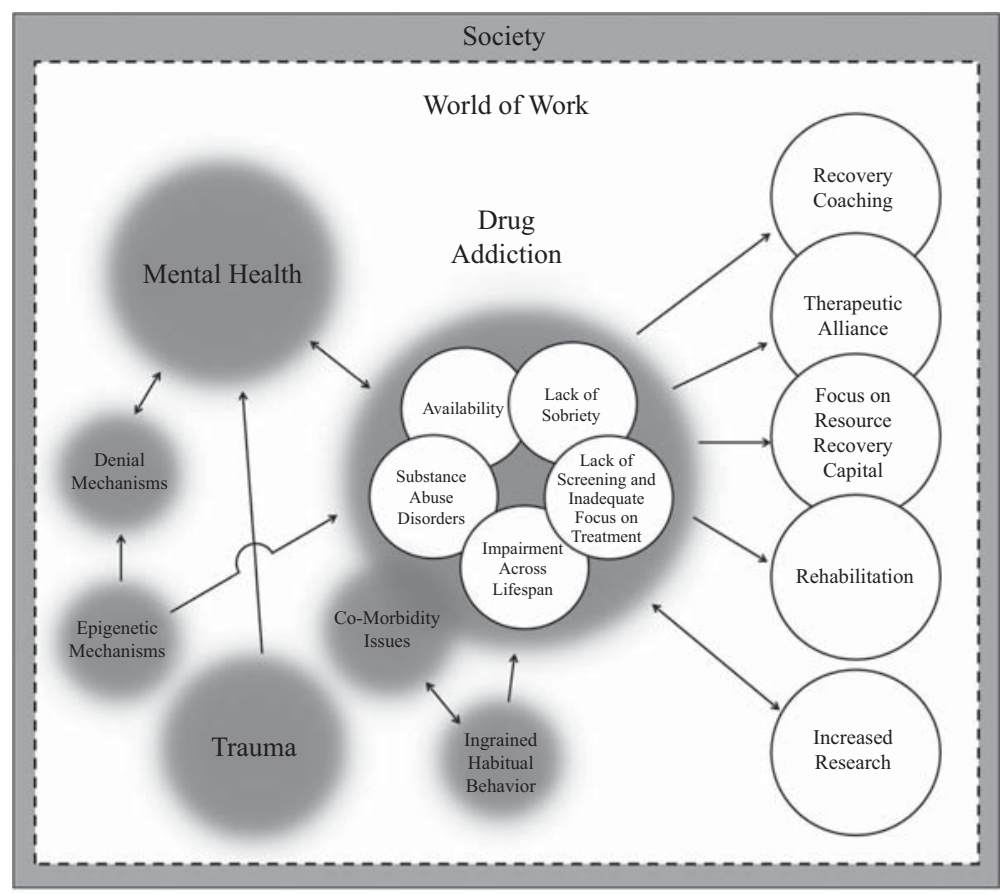


problems are the least standard (and least common) of all non-standard work-related problems. And thus while some commentators suggest drug addiction is a wicked problem (e.g. Alford and Head, 2017), it may in fact be super-wicked because many national policy responses, it can be argued, are resulting in tragedies for which traditional definitions and methods are ill equipped to finding sustainable solutions.

\section{Conclusion}

While WBL's focus on "problems" is well documented, the characteristics of work-related problems have remained mostly unexplored. The literature does indicate there are two main views of problems: one typified by seeing problems as definable, explainable and solvable in a relatively straightforward and logical manner using traditional scientific methods; and a second which considers causes and effects as ill-defined, hard to describe, fuzzy, disputed, complex and constantly changing, and therefore messy and resistant to standard approaches. Many of these types of problem are also viewed as co-produced, wicked and, in their most extreme form, catastrophic.

According to Schön, the former view suggests solutions may have technical merit but focus on problems which are relatively unimportant to organisations and society, while the latter recognises solutions are hard won but in doing so address problems which are more important. His challenge for us in WBL is whether to remain on the so-called "high hard ground" of research or whether we should "leap into the swamp" and face problems he considers more critical. In each case, the research lens through which we view the problem determines the types of questions we ask and investigate, and thus challenge the potential methods and solutions they suggest, an important point if research outcomes are to be valued and relevant in work contexts and in society.

The available evidence on the value of WBL to individual learning and professional development is well established, including benefits such as increased competence, confidence and motivation at work, a hunger for further learning, and promotion or increased responsibility (e.g. Costley and Abukari, 2015; Lester, 2015; Lester and Costley, 2010). But analysis of its benefit to organisations and society more broadly, and to new knowledge in particular, is in its infancy. As such, Boud et al. (2018, p. 915) have recently pointed out "there is [...] little research evidence of such an impact on the [...] organisation or workplace, nor the professional fields within which [practitioners] operate". Moreover, the contribution of WBL to address (let alone solve) many of the messy, co-produced and wicked problems related to work has yet to begin in earnest.

The purpose of this paper has therefore articulated what these types of problems are in an attempt to help understand work-related problems, and to appreciate their fundamental character by helping researchers recognise the complexity of problems and from there consider and develop more sustainable solutions for future organisations, work environments and society. Only such an understanding will enable WBL researchers to comprehend the scale and nature of the work-related problems they face.

\section{References}

Ackoff, R.L. (1979), "The future of operational research is past”, Journal of the Operational Research Society, Vol. 30 No. 2, pp. 93-104.

Alford, J. and Head, B.W. (2017), "Wicked and less-wicked problems: a typology and a contingency framework", Policy and Society, Vol. 36 No. 3, pp. 397-413.

Allan, D. (2015), "Conceptualising work learning: exploring the educational discourse on work-based, work-related, and workplace learning", Work Based Learning e-Journal International, Vol. 5 No. 1 , pp. 1-20. 
JWAM

11,2

Allen, G.M. and Gould, E.M. (1986), "Complexity, wickedness and public forests", Journal of Forestry, Vol. 84 No. 4, pp. 20-24.

Armsby, P., Costley, C. and Garnett, J. (2006), "The legitimisation of knowledge: a work-based learning perspective of APEL", International Journal of Lifelong Education, Vol. 25 No. 4, pp. 369-383.

Boyle, D. and Harris, M. (2009), The Challenge of Co-production: How Equal Partnerships Between Professionals and the Public are Crucial to Improving Public Services, Nesta, London.

Bjerg, O. (2008), "Drug addiction and capitalism: too close to the body", Body \& Society, Vol. 14 No. 2, pp. $1-22$.

Blackman, T. (2016), "The professional doctorate and the 21st century university", Work Based Learning e-Journal, Vol. 6 No. 1, pp. 1-7.

Boud, D., Fillery-Travis, A., Pizzolato, N. and Sutton, B. (2018), "The influence of professional doctorates on practice and the workplace", Studies in Higher Education, Vol. 43 No. 5, pp. 914-926.

Cornwall, A. and Jewkes, R. (1995), “What is participatory research?”, Social Science \& Medicine, Vol. 41 No. 12 , pp. 1667-1676.

Costley, C. and Abukari, A. (2015), "The impact of work-based research projects at postgraduate level", Journal of Work-Applied Management, Vol. 7 No. 1, pp. 3-14.

Costley, C., Elliot, G.C. and Gibbs, P. (2010), Doing Work Based Research: Approaches to Enquiry for Insider-Researchers, Sage Publications, Thousand Oaks, CA.

Dostal, E., Cloete, A. and Járos, G. (2005), Biomatrix: A Systems Approach to Organisational and Societal Change, 3rd ed., BiomatrixWeb, Cape Town.

Dostal, E., Cloete, A. and Járos, G. (2012), Biomatrix: A Systems Theory in Graphics, BiomatrixWeb, Cape Town.

Farrell, K.N. (2011), “Tackling wicked problems through the transdisciplinary imagination”, Journal of Environmental Policy \& Planning, Vol. 13 No. 1, pp. 75-77.

Fergusson, L., Allred, T. and Dux, T. (2018), "Work-based learning and research for mid-career professionals: professional studies in Australia”, Interdisciplinary Journal of e-Skills and Lifelong Learning, Vol. 14, pp. 1-17.

Fergusson, L., van der Laan, L. and Baker, S. (2019), "Reflective practice and work-based research: a description of micro- and macro-reflective cycles", Reflective Practice, Vol. 20 No. 2, pp. 289-303.

Fergusson, L., van der Laan, L., White, C. and Balfour, J. (2019), “The ethos and transformational nature of professional studies: a study of student experience in Australia", Higher Education, Skills and Work-Based Learning, doi: 10.1108/HESWBL-01-2019-0006.

Fulton, J. and Hayes, C. (2017), "Evaluating retrospective experiential learning as process in scholarship on a work based professional doctorate", Journal of Learning Development in Higher Education, Vol. 11, pp. 1-24.

Gibbs, P. (2009), "Learning agreements and work-based higher education", Research in Post-Compulsory Education, Vol. 14 No. 1, pp. 31-41.

Ginsburg, T. (Ed.) (2012), Comparative Constitutional Design, Cambridge University Press, Cambridge.

Häkkinen, P., Järvelä, S., Mäkitalo-Siegl, K., Ahonen, A., Näykki, P. and Valtonen, T. (2017), "Preparing teacher-students for twenty-first century learning practices (PREP 21): a framework for enhancing collaborative problem-solving and strategic learning skills", Teachers and Teaching, Vol. 23 No. 1, pp. 25-41.

Haskins, C. (2006), "Application of systems engineering and other disciplines to the design of a sustainable supply chain", CSER Paper No. 157, Corporate Social and Environmental Responsibility, University of Adelaide, Adelaide, pp. 7-8.

Hawkins, K.A. (2015), "The complexities of participatory action research and the problems of power, identity and influence”, Educational Action Research, Vol. 23 No. 4, pp. 464-478. 
Head, B.W. and Alford, J. (2015), "Wicked problems: implications for public policy and management", Administration \& Society, Vol. 47 No. 6, pp. 711-739.

Ioannidis, J.P. (2016), “Why most clinical research is not useful”, PLoS Medicine, Vol. 13 No. 6, pp. 1-10.

Jespersen, A.B., Hasle, P. and Nielsen, K.T. (2016), "The wicked character of psychosocial risks: implications for regulation”, Nordic Journal of Working Life Studies, Vol. 6 No. 3, pp. 23-42.

Kempster, S. and Stewart, J. (2010), "Becoming a leader: a co-produced autoethnographic exploration of situated learning of leadership practice", Management Learning, Vol. 41 No. 2, pp. 205-219.

Lachapelle, P.R., McCool, S.F. and Patterson, M.E. (2003), "Barriers to effective natural resource planning in a 'messy' world”, Society \& Natural Resources, Vol. 16 No. 6, pp. 473-490.

Lazarus, R.J. (2008), "Super wicked problems and climate change: restraining the present to liberate the future", Cornell Literature Review, Vol. 94, p. 1153.

Lelieveldt, H., Dekker, K., Völker, B. and Torenvlied, R. (2009), "Mapping and predicting the involvement of civic organizations in neighbourhood problem-solving and coproduction", Urban Affairs Review, Vol. 45 No. 1, pp. 3-24.

Lester, S. (2012), "A vocational qualifications system fit for adults? Revisiting some ideas from the University for Industry", Studies in Continuing Education, Vol. 34 No. 3, pp. 267-280.

Lester, S. (2015), "Creating original knowledge in and for the workplace: evidence from a practitioner doctorate", Higher Education, Skills and Work-Based Learning, Vol. 5 No. 2, pp. 102-116.

Lester, S. and Chapman, J. (2008), Beyond Conventional Competence: A Study of Capable People, Stan Lester Development, Taunton.

Lester, S. and Costley, C. (2010), "Work-based learning at higher education level: value, practice and critique", Studies in Higher Education, Vol. 35 No. 5, pp. 561-575.

Levin, K., Cashore, B., Bernstein, S. and Auld, G. (2012), "Overcoming the tragedy of super wicked problems: constraining our future selves to ameliorate global climate change", Policy Sciences, Vol. 45 No. 2, pp. 123-152.

Mehlman, M.A. (2006), "Causal relationship from exposure to chemicals in oil refining and chemical industries and malignant melanoma", Annals of the New York Academy of Sciences, Vol. 1076 No. 1, pp. 822-828.

Nixon, I., Smith, K., Stafford, R. and Camm, S. (2006), Work-Based Learning: Illuminating the Higher Education Landscape, The Higher Education Academy, York.

O’Brien, K., Fitzsimmons, T.W., Crane, M. and Head, B. (2017), "Workplace gender inequality as a wicked problem: implications for research and practice", Academy of Management Annual Meeting Proceedings, Briarcliff Manor, NY.

Polk, M. (2015), "Transdisciplinary co-production: designing and testing a transdisciplinary research framework for societal problem solving", Futures, Vol. 65, pp. 110-122.

Raelin, J.A. (1997), “A model of work-based learning”, Organisation Science, Vol. 8 No. 6, pp. 563-578.

Raelin, J.A. (2008), Work-Based Learning: Bridging Knowledge and Action in the Workplace, Wiley, New York, NY.

Raelin, J.A. (2011), "Work-based learning: how it changes leadership", Development and Learning in Organizations: An International Journal, Vol. 25 No. 5, pp. 17-20.

Rittel, H.W.J. and Webber, M.M. (1973), "Dilemmas in a general theory of planning", Policy Science, Vol. 4, pp. 155-169.

Rosenhead, J. (1992), "Into the swamp: the analysis of social issues", Journal of the Operational Research Society, Vol. 43 No. 4, pp. 293-305.

Schön, D.A. (1995), "Educating the reflective legal practitioner", Clinical Law Review, Vol. 2 No. 1, pp. 231-250.

Schön, D.A. (2016), The Reflective Practitioner: How Professionals Think in Action, Routledge, New York, NY. 
JWAM

11,2
Schwarz, E.D. and Kowalski, J.M. (1993), "Malignant memories: effect of a shooting in the workplace on school personnel's attitudes", Journal of Interpersonal Violence, Vol. 8 No. 4, pp. 468-485.

Siebert, S. and Walsh, A. (2013), "Reflection in work-based learning: self-regulation or self-liberation?", Teaching in Higher Education, Vol. 18 No. 2, pp. 167-178.

Sun, Q. and Kang, H. (2015), "Infusing work-based learning with Confucian principles: a comparative perspective", Higher Education, Skills and Work-Based Learning, Vol. 5 No. 4, pp. 323-338.

Thompson, R. (2011), "Reclaiming the disengaged? A Bourdieuian analysis of work-based learning for young people in England", Critical Studies in Education, Vol. 52 No. 1, pp. 15-28.

Toledano-O'Farrill, R. (2017), "Professional application projects: work-based learning in the curriculum", Higher Education, Skills and Work-Based Learning, Vol. 7 No. 1, pp. 21-34.

Vogel, C., Scott, D., Culwick, C.E. and Sutherland, C. (2016), "Environmental problem-solving in South Africa: harnessing creative imaginaries to address 'wicked' challenges and opportunities", South African Geographical Journal, Vol. 98 No. 3, pp. 515-530.

Werhane, P.H., Hartman, L.P., Moberg, D., Englehardt, E., Pritchard, M. and Parmar, B. (2011), "Social constructivism, mental models, and problems of obedience", Journal of Business Ethics, Vol. 100, pp. 103-118.

Yearworth, M. (2016), "Sustainability as a 'super-wicked' problem: opportunities and limits for engineering methodology”, Intelligent Buildings International, Vol. 8 No. 1, pp. 37-47.

\section{Corresponding author}

Lee Fergusson can be contacted at: lee.fergusson@usq.edu.au

For instructions on how to order reprints of this article, please visit our website: 